SINGULANO, Yara Lopes, TEIXEIRA, Karla Maria Damiano. Percepção de adolescentes sobre as causas da violência doméstica e familiar contra as mulheres. Oikos: Família e Sociedade em Debate, v. 31, n. 1 p.96-118, 2020. http://dx.doi.org/10.31423/oikos.v31i1.8979

\title{
PERCEPÇÃO DE ADOLESCENTES SOBRE AS CAUSAS DA VIOLÊNCIA DOMÉSTICA E FAMILIAR CONTRA AS MULHERES
}

\section{ADOLESCENTS' PERCEPTION REGARDING THE CAUSES OF DOMESTIC AND FAMILY VIOLENCE AGAINST WOMEN}

\section{PERCEPCIÓN DE ADOLESCENTES SOBRE LAS CAUSAS DE LA VIOLENCIA DOMÉSTICA Y FAMILIAR CONTRA LAS MUJERES}

\begin{abstract}
Yara Lopes Singulano ${ }^{1}$ Karla Maria Damiano Teixeira ${ }^{2}$

Resumo

Este artigo investiga a percepção de adolescentes sobre a violência doméstica e familiar cometida contra as mulheres, buscando identificar sua compreensão sobre as causas desse tipo de violência. Para a coleta de dados, foram analisadas 392 redações, escritas por alunos do ensino médio de uma escola pública. A análise dos dados indicou que, segundo os adolescentes, as principais causas da violência são o machismo, o uso de álcool e de drogas ilícitas, e, discordâncias entre o casal ou a família. Em sua maioria, os participantes não identificaram o componente da desigualdade de gênero como causa da violência doméstica e familiar contra as mulheres, ficando evidente a permanência de valores machistas entre os adolescentes, especialmente entre os do gênero masculino. Verificou-se, ainda, a grande influência do discurso midiático e de suas próprias vivências em família, já que não existe uma abordagem sistematizada e transversal sobre o tema na escola. Conclui-se que a falta de informação pode contribuir para a perpetuação de sua prática, através da naturalização da violência.
\end{abstract}

Palavras-chave: Violência doméstica contra as mulheres. Causas da violência. Educação. Mídia. Adolescentes.

\begin{abstract}
This paper investigates the perception of adolescents about the domestic and family violence against women, identifying their understanding about the causes of this type of violence. For the data collection, 392 essays, written by high school students of a public school, were analysed. The results showed that most participants did not identify the component of gender inequality as a cause of domestic and family violence against women. Besides that, there was a persistence of sexist values especially among male adolescents. It was verified the great influence of the media discourse and of the adolescents own experiences. The school system does not approach this theme in a transversal and continuous way, which can contribute to the lack of information about the domestic and family violence phenomenon. Consequently, there is a perpetuation of its practice, through the naturalization of violence.
\end{abstract}

Keywords: Domestic violence against woman. Causes of the violence. Education. Media. Adolescents.

\section{Resumen}

Este artículo investiga la percepción de los adolescentes de la violencia doméstica y familiar contra las mujeres, buscando identificar su comprensión de las causas de este tipo de violencia. Para la recolección de datos, se analizaron 392 ensayos, escritos por estudiantes de secundaria de una escuela pública. El análisis de los datos indicó que, según los adolescentes, las principales causas de violencia son el machismo, el uso de alcohol y drogas ilícitas, y los desacuerdos entre la pareja o la familia. La mayoría de los participantes no identificaron el componente de desigualdad de género como una causa de violencia doméstica y familiar contra las mujeres, y la permanencia de los valores sexistas entre los adolescentes, especialmente entre los hombres, es evidente. También hubo una gran influencia del discurso de los medios y sus propias experiencias familiares, ya que no existe un enfoque sistemático y transversal al tema en la escuela. Se concluye que la falta de información puede contribuir a la perpetuación de su práctica, a través de la naturalización de la violencia.

Palabras clave: Violencia doméstica contra la mujer. Causas de violencia. Educación. Medios de comunicación. Adolescentes.

${ }^{1}$ Bacharela em Direito e Mestra em Economia Doméstica (UFV). Advogada. Professora assistente dos cursos de graduação de Direito e de Administração da Unifagoc - Ubá/MG. E-mail: yarasingulano@hotmail.com

$2 \mathrm{PhD}$ em Family and Child Ecology pela Michigan State University. Professora Titular do Departamento de Economia Doméstica da Universidade Federal de Viçosa. E-mail: kdamiano@ufv.br 


\section{INTRODUÇÃO}

A violência contra as mulheres é uma grave violação aos direitos humanos, perpetrada há muitos séculos, presente em diversos povos e culturas, mas que adquiriu visibilidade a partir do século XX (ALVES, 2005; DIAS, 2012). Os movimentos feministas, que questionaram a sacralidade do lar, trazendo à tona nos debates públicos questões antes tidas como privadas, constituíram o principal mote para essa mudança de paradigma.

A consolidação do feminismo enquanto movimento político propiciou a emergência de uma abordagem crítica da família, problematizando a tradicional interpretação que restringia o núcleo familiar a um espaço de conforto, harmonia e comunhão fraternal, ignorando que diferentes opressões e violências podem ser perpetradas por seus membros (ALVES, 2005; GIDDENS, 2005). Nesse sentido, destaca-se que a violência contra as mulheres, por ser derivada de uma estrutura social patriarcal e misógina, é, majoritariamente, cometida por conhecidos, em âmbito doméstico e familiar (GIDDENS, 2005; PASINATO, 2016), e, especialmente, por parceiros ou ex-parceiros íntimos, padrão este que não se repete entre a violência que acomete a população masculina (WAISELFISZ, 2015).

Waiselfisz (2015) aponta que o Brasil possui o 5 maior índice de feminicídio na classificação da Organização Mundial de Saúde (OMS) que considerou 83 países, atestandose um dos países mais violentos do mundo para as mulheres. É preciso considerar, ainda, que a violência doméstica e familiar é subnotificada, sendo difícil conceber a real dimensão que esse tipo de violência ocupa (IPEA, 2014). Trata-se de uma verdadeira epidemia, que pode ser associado ao patriarcalismo e ao machismo arraigados na cultura brasileira, herança de nossa colonização (CABRAL, 1999), mas que é agravada pela alta desigualdade social do país, conforme lembram Sequeira e Stella (2012).

Devido à gravidade do problema, em 2006 foi sancionada, pelo então presidente Luís Inácio Lula da Silva, a Lei Maria da Penha - Lei n 11.340, que "cria mecanismos para coibir a violência doméstica e familiar contra a mulher" (BRASIL, 2006, preâmbulo). A referida lei é apontada como uma das mais avançadas legislações de proteção à mulher do mundo, pela Organização das Nações Unidas (ONU), destacando-se por promover a abordagem integral da violência, ao invés de tratá-la como mera questão criminal (PASINATO, 2015; CAMPOS, 2017).

Não obstante os avanços conquistados desde a promulgação da Lei Maria da Penha, Waiselfisz (2015) demonstra que, no Brasil, as taxas de violência contra mulheres vêm aumentando gradativamente desde a década de 1980, indicando que as ações governamentais implementadas têm sido insuficientes. Parte do problema é que muitos estigmas e preconceitos 
sobre a violência doméstica e familiar ainda permeiam o imaginário social, dificultando a erradicação da violência contra as mulheres (IPEA, 2015). O predomínio de uma cultura machista faz com que a população tolere, e até mesmo incentive, a violência doméstica e familiar (RITT; CAGLIARI; COSTA, 2009).

Por conseguinte, para erradicar esse tipo de violência é necessária uma mudança social, um ajuste na estrutura patriarcal que sustenta as desigualdades de gênero, que, em última instância, fomentam a violência doméstica e familiar contra as mulheres (CARVALHO, 2015; UNICEF, 2015). Nesse sentido, tem-se enfatizado a necessidade de ações visando a conscientização e sensibilização da população sobre o tema, ainda rodeado de tabus, e que foquem especialmente nos grupos etários mais jovens, o que possibilita a prevenção primária da violência (OMS, 2012; ONU MULHERES, 2014; PLAN INTERNACIONAL BRASIL, 2014).

Partindo dessas considerações, este trabalho objetivou desvelar tanto o nível de conhecimento objetivo, quanto às concepções morais e subjetividades, de um grupo de adolescentes, alunos do ensino médio de uma escola pública do interior de Minas Gerais.

Problematizou-se que, ao não terem acesso formal, na escola, a informações sobre o fenômeno da violência doméstica e familiar contra as mulheres, os adolescentes não desenvolvem a perspectiva de que se trata de um problema social, naturalizam a violência e tornam-se meros reprodutores das situações vivenciadas, o que contribui para a continuidade das práticas violentas.

\section{ABORDAGEM METODOLÓGICA}

Realizou-se um estudo do tipo exploratório-descritivo sobre a percepção de adolescentes, alunos das três séries do ensino médio de uma escola pública do interior de Minas Gerais, acerca do fenômeno da violência doméstica e familiar contra as mulheres. $O$ colégio é o único público a oferecer ensino médio no município; a maioria de seus alunos reside na zona rural e se desloca até a cidade para estudar.

A escolha do local da pesquisa remete às considerações de Sequeira e Stella (2012), que, em seu estudo bibliométrico, averiguaram que a maior parte dos estudos empíricos brasileiros sobre violência doméstica e familiar está centrada no eixo Rio-São Paulo, nas grandes metrópoles. Buscou-se, então, uma amostra que fugisse do citado padrão dominante. Também foi levado em consideração o recente processo de transição pelo qual tem passado o Brasil, caracterizado pela disseminação e a interiorização da violência, conforme destaca Waiselfisz (2011). Mais especificamente, Waiselfisz (2015) aponta que os municípios brasileiros 
de pequeno porte (entre 20 e 50 mil habitantes) são os que possuem as maiores taxas ${ }^{3}$ de homicídios de mulheres. Assim, optou-se por realizar a pesquisa em Ervália-MG, uma cidade com menos de 20 mil habitantes, eminentemente rural (IBGE, 2016).

Por sua vez, a opção metodológica pela amostra, composta por alunos do ensino médio, advém da necessidade de incrementar os debates com foco na adolescência, que é pouco utilizada em estudos, apesar das vastas evidências de que ações voltadas às faixas etárias mais jovens são muito eficientes para promover a prevenção da violência, o que torna relevantes os estudos envolvendo essa população (CÓRDOBA, 2006; SANTOS; MORA; DEBIQUE, 2016). Mesmo a nível internacional, parece persistir essa lacuna no campo de pesquisa, como destacam Franco, López-Cepeiro e Díaz (2009). Os autores indicam a necessidade de ampliar as investigações com foco na adolescência, ao concluir que amostras de adolescentes são pouco utilizadas, e que tais estudos geralmente se concentram no espectro da vítima ou testemunha da violência.

Para a coleta de dados, foi solicitado às professoras de Língua Portuguesa que aplicassem em cada turma uma redação, a ser desenvolvida em aula. Os alunos foram orientados a elaborar um texto dissertativo, de até 30 linhas, respondendo algumas questões norteadoras. Neste artigo, analisam-se as respostas sobre a seguinte questão: "quais são as causas da violência doméstica e familiar contra as mulheres, ou seja, por que existe esse tipo de violência?".

Foi pedido às professoras que a atividade fosse desenvolvida como uma atividade curricular comum, sem fazer menção à pesquisa. A decisão de não informar aos alunos do que se tratava, de fato, a redação, foi tomada a fim de que os textos fossem construídos de forma mais espontânea, para revelar um panorama tão fidedigno quanto possível das opiniões e conhecimentos dos adolescentes sobre o tema. Flick (2009) e Gray (2012) recomendam o uso do segredo na pesquisa somente em situações específicas, nas quais revelar aos participantes de que são parte de um estudo pode prejudicar os resultados obtidos, ou mesmo impossibilitar a realização do mesmo. Considerando que o assunto violência, por si só, é bastante delicado, e somando-se a isso o fato de os participantes serem bastante jovens, a presença da pesquisadora e/ou a menção da realização da pesquisa poderiam intimidar os participantes, de modo que se mostrou mais interessante essa opção metodológica. Não obstante, todas as precauções para resguardar a ética da pesquisa foram tomadas, e o projeto de pesquisa foi aprovado pelo Comitê de Ética da instituição (parecer nํㅜㅇ.098.213).

${ }^{3} \mathrm{O}$ autor realiza projeções, com taxas baseadas em número de homicídios de mulheres por cem mil habitantes. 
Foram produzidas 392 redações ao todo, por alunos das três séries do ensino médio (1ํㅡ, 2ำ e 3ำ ano) do turno matutino. No início do ano letivo de 2017, havia 510 alunos matriculados nas treze turmas do ensino médio matutino, sendo 285 do gênero feminino e 225 do masculino. O número de redações foi inferior ao número de alunos efetivamente matriculados devido a algumas questões: primeiramente, devido a eventuais faltas de alunos no dia em que a atividade foi realizada; em segundo lugar, cinco alunos do gênero masculino (sendo dois alunos do $1^{\circ}$ ano, e três alunos do $2^{\circ}$ ano) não escreveram a redação, e entregaram a folha em branco às professoras. A Tabela 1 indica a relação entre alunos matriculados no início do ano letivo, e o número de redações produzidas.

Tabela 1. Comparação entre número de alunos matriculados e de redações produzidas: total, por série e por gênero.

\begin{tabular}{|c|c|c|c|c|}
\hline & Masculino & Feminino & Total \\
\hline \multirow{4}{*}{$\begin{array}{l}\text { Número de alunos matriculados } \\
\text { no início do ano letivo }\end{array}$} & Ensino médio & 225 & 285 & 510 \\
\hline & 10 ano & 73 & 96 & 169 \\
\hline & $2^{\circ}$ ano & 78 & 105 & 183 \\
\hline & $3^{\circ}$ ano & 74 & 84 & 158 \\
\hline \multirow[t]{4}{*}{ Número de redações produzidas } & Ensino médio & 167 & 225 & 392 \\
\hline & $1^{\circ}$ ano & 51 & 83 & 134 \\
\hline & $2^{\circ}$ ano & 60 & 71 & 131 \\
\hline & $3^{\circ}$ ano & 56 & 71 & 127 \\
\hline
\end{tabular}

Fonte: dados de pesquisa (2017).

Para análise dos dados, o método utilizado foi a análise de conteúdo, proposta por Bardin (2011). Realizou-se o exame sistemático dos textos, a partir das questões norteadoras propostas, que transmutaram-se em categorias de análise, e feita a pré-análise dos textos, visando a organização e sistematização das informações; em seguida, foi realizada a codificação, agrupando as redações em unidades de registro, e a categorização semântica (por tema), seguindo o sistema de grade mista; passando, então, à análise propriamente dita, via inferência e interpretação. As categorias definidas para análise foram os tipos de abordagens encontrados nas redações, tendo se destacado três: os valores machistas que predominam na sociedade (apresentam perspectiva de gênero, embora não mencionem o termo); uso de álcool e outras drogas pelo agressor; discordância do casal, ou de familiares, sobre alguma questão (não apresentam perspectiva de gênero). Um mesmo texto poderia abarcar, concomitantemente, mais de uma causa para a violência, sendo enquadrado em mais de uma categoria, portanto. 


\section{FUNDAMENTAÇÃO TEÓRICA}

A partir da consolidação do movimento feminista, os estudos sobre as famílias passam a assumir que o ambiente doméstico é, na verdade, propício para o desenvolvimento de diversos conflitos, que podem se agravar e, inclusive, culminar em episódios de violência doméstica e familiar. A respeito, Giddens (2005) afirma que, embora, para muitos, a família seja espaço de alívio e conforto perante as dificuldades da vida, este pode ser também um lugar de exploração, desigualdade e mesmo de solidão.

De fato, o ambiente familiar é onde ocorre a maior parte das violências cometidas contra crianças, idosos e mulheres, partes hipossuficientes nas relações familiares patriarcais, nas quais quem detém a autoridade é o homem provedor do lar (ALVES, 2005; RABELO, 2008). Giddens (2005) associa a universalidade da violência doméstica e familiar, verificável em todas as culturas e classes sociais, a dois fatores em especial: a intensidade emocional e a intimidade que permeiam as relações familiares, o que as torna mais "explosivas"; e a tolerância à violência no âmbito familiar, que, segundo o autor, é até mesmo aprovada, enquanto método disciplinador.

É importante assumir essa perspectiva crítica, abandonando o mito da família perfeita, pois a sua idealização somente leva à invisibilidade do problema da violência intrafamiliar (ALVES, 2005). Dias (2012) salienta que a inviolabilidade da família, antes intocável pelo Estado, somente contribuiu para silenciar os acontecimentos domésticos, estabelecendo um ciclo vicioso de violência que, não denunciada, se perpetua e se agrava. Entender que o conflito é inerente à organização familiar desloca as discussões para a necessidade de administração dos conflitos; nesse sentido, são muito ricas as contribuições da Teoria do Conflito Familiar (INGOLDSBY; SMITH; MILLER, 2004; SAXBE; RODRIGUES; MARGOLIN, 2013).

Na teoria sociológica de Georg Simmel, o conflito não somente é um fenômeno natural da vida em sociedade, dada a escassez de recursos disponíveis e o grande número de necessidades a serem satisfeitas, como também é necessário para a sua manutenção. A disputa tem um indissociável caráter socializador, propiciando a unidade social, seja pela resolução amigável entre as partes (quando os indivíduos cooperam entre si e negociam seus interesses), seja pelo aniquilamento de uma delas (quando indivíduos de um grupo se unem para fazer seus interesses preponderarem sobre os de outro) (SANTOS, 2014; SIMMEL, 2016). Outrossim, o pressuposto fundamental da Teoria do Conflito Familiar é que o conflito social é 
"um elemento básico da vida social humana" (RABELO, 2008, p. 16), uma condição inevitável e endêmica (WHITE; KLEIN, 1996).

O conflito familiar, em particular, se origina a partir da desigualdade de recursos entre indivíduos membros de um mesmo grupo, visto que os recursos são distribuídos de forma diferenciada conforme idade e gênero, principalmente. Essa desigualdade na distribuição dos recursos pode levar a conflitos na medida em que as normas internas da família sejam competitivas, e não cooperativas, transformando os seus membros em competidores - reais ou potenciais (WHITE; KLEIN, 1996).

Aqui, recursos tratam-se de todos os conhecimentos, habilidades, técnicas e materiais de que um indivíduo ou grupo dispõe, sendo que o conceito de recurso está intimamente ligado à ideia de poder e de autoridade. Recursos podem oferecer uma base para o exercício do poder, aqui entendido como a capacidade de um indivíduo ou grupo controlar efetivamente outros; deter recursos é, potencialmente, deter poder. Contudo, um elemento, em especial, é necessário para que haja o efetivo exercício do poder: a autoridade.

A autoridade é o recurso construído com base nas normas sociais vigentes em cada cultura, e que legitima o uso dos demais recursos, possibilitando o efetivo exercício do poder (WHITE; KLEIN, 1996). Na família patriarcal, as duas principais formas de diferenciação estrutural são gênero e idade (INGOLDSBY; SMITH; MILER, 2004). A partir dessas categorias há uma assimetria entre os membros da família no acesso aos recursos e, consequentemente, ao poder, relegando mulheres, crianças e idosos a uma posição desprivilegiada em nossa sociedade (RITT; CAGLIARI; COSTA, 2009; PEREIRA, 2012). Assim, a perspectiva de gênero não pode ser afastada de qualquer análise sobre o conflito familiar.

Nesse contexto, a violência contra as mulheres emerge como uma tentativa masculina de manter o status quo da distribuição de recursos (e, portanto, de poder), alimentada por uma cultura de violência que permeou todo o processo de formação da sociedade brasileira (SEQUEIRA; STELLA, 2012). No entanto, a violência intrafamiliar não é fruto do conflito em si, mas sim da incapacidade dos membros da família de lidarem com esse conflito racionalmente, gerindo-o. A impossibilidade, ou incapacidade, de utilizar outros recursos, como o diálogo e a argumentação, levam ao uso da violência, especialmente pelos homens (RITT; CAGLIARI; COSTA, 2009).

Sistemas sociais rígidos favorecem a emersão de rupturas violentas e radicais, enquanto sistemas mais flexíveis ajustam-se às mudanças no equilíbrio de poder, pois, ao permitirem a liberdade de conflito, reestabelecem o equilíbrio interno do sistema (COSER, 1957). Em outras palavras, a negociação como forma de gerir conflitos é mais propensa a dar resultados 
positivos em estruturas de arranjos mais democráticos, nos quais a autoridade está distribuída entre os membros. Em grupos organizados de forma democrática, com a autoridade distribuída, também é mais comum que se formem coalisões entre membros, que unem seus recursos para ter maior poder de negociação, gerando certo equilíbrio de forças. Em grupos nos quais os recursos, e, por conseguinte, o poder, estão concentrados, o processo de negociação é mais difícil (WHITE; KLEIN, 1996). A rígida organização das famílias a partir de papeis sociais pré-determinados e estigmatizados para homens (provedores, chefes da família, austeros, dominantes) e mulheres (cuidadoras, emotivas, frágeis, submissas) potencializa a ocorrência de conflitos, mediante a impossibilidade de se reproduzir esses padrões nas relações contemporâneas (SEQUEIRA; STELLA, 2012). Para Camargo (2002, p. 56), pode-se "considerar que as interações violentas de um casal estão vinculadas ao aumento de tensão nas relações de poder estabelecidas e que a relação de dominação/subordinação necessita ser confirmada".

A violência doméstica e familiar é um fenômeno complexo, que emerge a partir da combinação de diversas características, sociais, econômicas, psicológicas, culturais, manifestadas a nível pessoal ou coletivo (ALVES, 2005). Nenhum desses fatores age sozinho; trata-se da interação de diversas condições, como ressalta Carvalho-Barreto (2009), para quem "essa violência não é originada por único agente, mas é resultado da ação sistêmica de fatores diversos" (p. 08). É certo que alguns fatores de risco indicam maior probabilidade para a ocorrência de violência em âmbito doméstico ou familiar, como: baixo nível de escolaridade, falta de acesso à informação, pobreza, abuso de álcool e outras drogas, ter presenciado ou sofrido violência na infância (CABRAL, 1999; OMS, 2012).

Importante frisar que a violência doméstica e familiar contra as mulheres, embora possa, por vezes, ser verificada de forma mais explícita em famílias de baixo nível socioeconômico, é um fenômeno presente em todas as classes sociais, diferenciando-se apenas quanto às formas de manifestação (ALVES, 2005, PEREIRA et al, 2013). Algumas situações ou características podem agir como desencadeadores ou agravantes da violência, mas não como causa exclusiva; deve-se, assim, evitar o estigma que associa pobreza à violência ( $\mathrm{ROCHA}$; GONÇALVES; DAROSSI, 2009; SEQUEIRA; STELLA, 2012).

Do mesmo modo, é preciso problematizar afirmações simplistas que se propagam, especialmente, na abordagem midiática, e associam a violência doméstica e familiar contra as mulheres a eventos específicos, ou a características pessoais de vítima ou agressor, desconsiderando o cenário macrossocial ("matou por ciúme"; "bateu porque estava embriagado"; "matou porque foi traído"; e formulações afins). Para Blay (2003), existe "uma 
recorrente dramatização romântica do amor passional, sobretudo na televisão e no rádio, em que realidade e imaginário se retroalimentam" (p. 05). Assim, a mídia fomenta no espectador uma sensação de compreensão/empatia diante da conduta do agressor, que é perdoado porque "agiu por amor", como aponta Vianna (2010). Em contraponto, a vítima é frequentemente culpabilizada, sobretudo quando sua conduta é considerada imoral ou inadequada para os padrões sociais. Para Miranda (2017, p. 358), quando se trata de violência de gênero, a "narrativa jornalística tem sido permeada de sensacionalismo, dramaticidade e espetacularização", pois desconsidera a perspectiva de gênero e não aborda as desigualdades entre homens e mulheres como fator primordial para a ocorrência desse tipo de violência; e, principalmente, porque não contribui para a sensibilização da população sobre a violência contra as mulheres enquanto um grave problema social brasileiro - ao contrário, perpetua estereótipos machistas e estigmas sobre a violência.

\section{RESULTADOS E DISCUSSÃO}

Inicialmente, procurou-se verificar as causas da violência doméstica e familiar contra as mulheres, de acordo com a percepção dos adolescentes.

Observou-se que a maior parte dos textos mencionava comportamentos que julgavam dar causa à violência, tendo sido identificadas respostas tão diversas que não seria viável apresentá-las individualmente. Contudo, foi possível identificar a prevalência de três tipos de abordagens, e alocar as citadas condutas nessas categorias, que foram definidas como os eixos temáticos da análise, conforme Tabela 2.

Apenas 5,6\% dos participantes não abordaram, em suas redações, o tópico proposto. Dentre as redações que responderam à questão, a maioria citou mais de uma causa para a violência, de modo que um mesmo texto poderia estar elencado em mais de uma das categorias da Tabela 2.

As abordagens mais frequentes apontaram como causas da violência doméstica e familiar contra as mulheres: 1) os valores machistas que predominam na sociedade (respostas que apresentaram perspectiva de gênero); 2) uso de álcool e outras drogas pelo agressor; 3) discordância do casal, ou de familiares, sobre alguma questão (não apresentaram perspectiva de gênero). Demais respostas, cuja frequência de repetição foi muito baixa, foram enquadradas na categoria "outros". 
Tabela 2. Causas da violência doméstica e familiar contra as mulheres, Ervália-MG, 2017.

\begin{tabular}{|c|c|c|c|c|c|c|c|}
\hline \multirow[t]{3}{*}{ Série } & \multirow[t]{3}{*}{ Questões } & \multicolumn{4}{|c|}{ Gênero } & \multirow{2}{*}{\multicolumn{2}{|c|}{ Total }} \\
\hline & & \multicolumn{2}{|c|}{ Masculino } & \multicolumn{2}{|c|}{ Feminino } & & \\
\hline & & \begin{tabular}{|l|} 
№ \\
\end{tabular} & $\%$ & № & $\%$ & № & $\%$ \\
\hline \multirow[t]{6}{*}{ 10 ano } & Total & 50 & 100 & 84 & 100 & 134 & 100 \\
\hline & 1.Não responderam & 4 & 8 & 5 & 6 & 9 & 6,7 \\
\hline & $\begin{array}{l}\text { 2. Associaram ao machismo e/ou } \\
\text { desigualdades de gênero }\end{array}$ & 18 & 36 & 47 & 56 & 65 & 48,5 \\
\hline & $\begin{array}{l}\text { 3. Uso de álcool/drogas pelo } \\
\text { agressor }\end{array}$ & 24 & 48 & 42 & 50 & 66 & 49,2 \\
\hline & $\begin{array}{l}\text { 4. Discordância do casal, ou de } \\
\text { familiares, sobre alguma questão }\end{array}$ & 17 & 34 & 22 & 26,2 & 39 & 29,1 \\
\hline & 5. Outros & 9 & & 18 & & 27 & 20,1 \\
\hline \multirow[t]{6}{*}{$2^{\circ}$ ano } & Total & 60 & 100 & 71 & 100 & 131 & 100 \\
\hline & 1. Não responderam & 2 & 3,1 & 4 & 5,6 & 6 & 4,5 \\
\hline & $\begin{array}{l}\text { 2. Associaram ao machismo e/ou } \\
\text { desigualdades de gênero }\end{array}$ & 13 & 21,6 & 32 & 45 & 45 & 34,4 \\
\hline & $\begin{array}{l}\text { 3. Uso de álcool/drogas pelo } \\
\text { agressor }\end{array}$ & 20 & 33,3 & 24 & 33,8 & 44 & 33,6 \\
\hline & $\begin{array}{l}\text { 4. Discordância do casal, ou de } \\
\text { familiares, sobre alguma questão }\end{array}$ & 31 & 51,6 & 20 & 28,1 & 51 & 38,9 \\
\hline & 5. Outros & 11 & 18,3 & 15 & & 26 & 19,8 \\
\hline \multirow[t]{6}{*}{ 3ำ ano } & Total & 56 & 100 & 71 & 100 & 127 & 100 \\
\hline & 1. Não responderam & 5 & 8,9 & 2 & 2,8 & 7 & 5,5 \\
\hline & $\begin{array}{l}\text { 2. Associaram ao machismo e/ou } \\
\text { desigualdades de gênero }\end{array}$ & 26 & 46,4 & 47 & 66,2 & 73 & 57,5 \\
\hline & $\begin{array}{l}\text { 3. Uso de álcool/drogas pelo } \\
\text { agressor }\end{array}$ & 13 & 23,2 & 26 & 36,6 & 39 & 30,7 \\
\hline & $\begin{array}{l}\text { 4. Discordância do casal, ou de } \\
\text { familiares, sobre alguma questão }\end{array}$ & 13 & 23,2 & 16 & 22,5 & 68 & 53,5 \\
\hline & 5. Outros & 12 & 21,4 & 14 & 19,7 & 26 & 20,4 \\
\hline \multirow[t]{6}{*}{ Total } & Total & 167 & 100 & 225 & 100 & 392 & 100 \\
\hline & 1. Não responderam & 11 & 6,5 & 11 & 4,9 & 22 & 5,6 \\
\hline & $\begin{array}{l}\text { 2. Associaram ao machismo e/ou } \\
\text { desigualdades de gênero }\end{array}$ & 57 & 34,1 & 126 & 56 & 183 & 46,7 \\
\hline & $\begin{array}{l}\text { 3. Uso de álcool/drogas pelo } \\
\text { agressor }\end{array}$ & 57 & 34,1 & 92 & 40,9 & 149 & 38 \\
\hline & $\begin{array}{l}\text { 4. Discordância do casal, ou de } \\
\text { familiares, sobre alguma questão }\end{array}$ & 61 & 36,5 & 58 & 25,8 & 109 & 27,8 \\
\hline & 5. Outros & 32 & 19,2 & 47 & 20,9 & 79 & 20,2 \\
\hline
\end{tabular}

Fonte: dados de pesquisa (2017).

Nas redações analisadas, o agressor foi majoritariamente relacionado ao sexo masculino, e as poucas redações que abordaram a possibilidade de uma agressora mulher o fizeram mencionando a violência materna contra os filhos, distanciando-se da perspectiva 
proposta para a redação, cujo tema era a violência doméstica e familiar contra as mulheres, especificamente.

A questão do ciúme (masculino), a traição (feminina) e a não aceitação do término de um relacionamento (pelo homem) apareceram em quase todas as redações como fatos que podem desencadear a violência doméstica e familiar contra as mulheres. A sua ampla citação pode estar relacionada ao modo como a mídia divulga os crimes cometidos contra mulheres, já que é comum a menção a esses tipos de situação para contextualizar os episódios de violência, sobretudo feminicídio. Relevante mencionar, todavia, que foram identificadas redações com dois tipos de abordagem diferentes sobre essas situações: em alguns textos, os adolescentes apontaram-nas como desdobramento dos valores machistas que predominam na sociedade, que permitem que os homens se sintam no direito de controlar as mulheres com quem se relacionam; e, em outros, foram apresentadas como fatos aleatórios que podem levar ao desentendimento, sem vislumbrar a perspectiva de gênero que permeia esse tipo de violência. Assim, embora citem o mesmo tipo de situação fática, por terem desenvolvidos argumentações distintas, essas redações foram alocadas em categorias de análise diferentes.

\section{Machismo}

Das 392 redações analisadas, 183 (46,6\%) identificaram a predominância de valores machistas na sociedade como causa da violência doméstica e familiar contra as mulheres. Nessa categoria, foram enquadradas somente as redações que traziam explicitamente expressões que denotassem perspectiva de gênero em sua abordagem, como "machismo", "machista", "desigualdade entre homens e mulheres". Ressalta-se que o termo "gênero" foi utilizado em apenas duas das 393 redações, indicando amplo desconhecimento a respeito dessa categoria.

Esses participantes indicaram, de forma expressa, que a violência ocorre porque os homens sentem-se superiores às mulheres, e querem tratá-las como propriedades suas, verdadeiros objetos, controlando como se vestem, o que fazem, com quem conversam; quando não são atendidos nesse sentido, os homens rebelam-se contra a insubordinação feminina usando a violência. É o que se extrai dos trechos a seguir.

As causas mais comuns de violência dentro de casa é o machismo, pois homens acham que as esposas são escravas do lar, escrava sexuais, e tudo que acontece em casa e o homem não concorda, ele espanca, xingam, e maltratam na frente dos próprios filhos. ( $2^{\circ}$ ano, masculino)

Violência doméstica e familiar é um problema grave cometido contra as mulheres, normalmente por seus maridos machistas. Esses homens acham que podem mandar ou controlar a vida delas, e se elas não aceitam, são agredidas. ( $1^{\circ}$ ano, masculino) 
É visível que em pleno século XXI, o machismo continua se pronunciando. Apesar das várias conquistas realizadas pelas mulheres, a desigualdade de gênero ainda é algo preocupante, e isso contribui para que parte da população masculina sinta-se superior ao sexo oposto, influenciando a prática de violência. (3ำ ano, feminino)

A agressividade masculina foi relacionada a uma forma de vingança contra a mulher que contrariou, de alguma maneira, o agressor; ou como forma de controle, para mostrar para a vítima quem detém o comando da relação. Essas considerações dos participantes coincidem com as colocações da literatura, como as que fazem Dias (2012), Sequeira e Stella (2012) e Cabral (1999).

Cabral (1999) considera que a insubordinação feminina, assim entendida como qualquer desvio de conduta que fuja aos estereótipos dos papeis sociais que são pré-determinados às mulheres (de cuidado, afetividade, submissão, fragilidade), é a principal causa da violência doméstica e familiar. A inserção da mulher no mercado de trabalho, o desenvolvimento de métodos contraceptivos e outras mudanças advindas da luta emancipatória feminina abalaram os tradicionais papeis de gênero atribuídos a homens e mulheres. O conflito surge quando existe discrepância entre as regras pré-estabelecidas e a realidade do grupo, o que obriga seus membros a renegociarem essas regras. Contudo, essa mudança gera insegurança, que pode culminar em violência diante da negativa masculina de rever seus privilégios. A violência masculina é, então, socialmente justificada pelo descumprimento do papel ideal que cabia à mulher (WHITE; KLEIN, 1996; DIAS, 2012).

A violência doméstica e familiar contra as mulheres possui a particularidade de constituir-se a partir de um padrão repetitivo, que envolve controle e dominação, ao invés de agressões isoladas (DAY et al, 2003). Bonetti, Pinheiro e Ferreira (2008), ao analisarem dados referentes ao ano de 2007 do "Ligue 180", serviço governamental de atendimento a mulheres em situação de violência, apontam que a maioria das agressões denunciadas ocorria diária (61\%) ou semanalmente (16\%). Esse padrão repetitivo indica que a violência doméstica e familiar é, intrinsecamente, uma demonstração de poder dos homens para e sobre as mulheres. O exercício da violência é uma forma de os homens manterem-se dominantes nas relações afetivas e familiares, perpetuando os modelos patriarcais transmitidos por gerações como ideal social (ALVES, 2005; SEQUEIRA; STELLA, 2012). Nesse sentido, Dias (2012) apresenta dados que indicam que grande parte das mulheres vítimas de violência masculina associa a agressão ao controle de fidelidade e à insatisfação dos homens perante a busca das mulheres por maior autonomia.

A violência é a tentativa de condicionar o comportamento das mulheres desviantes, que recorrentemente são culpabilizadas pelas agressões que sofrem. Enquanto obedecem aos 
papeis que lhes são impostos, de submissão e servidão, as mulheres são tratadas como "rainhas do lar"; quando se rebelam, são corrigidas, majoritariamente por meio de mecanismos violentos - insultos, estupros, espancamentos, feminicídios (RITT; CAGLIARI; COSTA, 2009).

Ainda quanto aos resultados obtidos, frisa-se que esses participantes abordaram o machismo como um fator cultural, socialmente construído, indicando que entendem que a violência contra as mulheres não é natural, mas resultado de arranjos sociais.

\footnotetext{
Vivemos numa sociedade quase totalmente patriarcal, onde a figura do homem é sempre vista como mais importante. [...] Os ideais e valores patriarcais são repassados pela família e também pela escola. (3ำ ano, masculino)

O problema é que a nossa sociedade é muito machista, as crianças (meninos) já crescem com a ideia de que eles são superiores às mulheres. ( $2^{\circ}$ ano, feminino)
}

Joan Scott ressalta que o gênero é a primeira classificação utilizada para dar significado às relações de poder (SCOTT, 2005; GUIMARÃES, 2012). Remete, assim, às ideias propagadas por Engels (2014), segundo o qual a primeira divisão de classes se pautou no gênero. Surge, daí, o modelo de organização social denominado patriarcado, caracterizado pela sistemática primazia do gênero masculino sobre o feminino, cabendo aos homens o poder político, econômico e moral, e a autoridade para exercê-los (GUIMARÃES, 2012; SOUSA; ASTIGARRA, 2015).

Nas sociedades patriarcais, os papeis sociais destinados a homens e mulheres são bem distintos entre si: enquanto cabem aos homens os papeis de dominação e de poder, de provedores, as mulheres devem ser submissas, cuidadoras da família e do lar (SEQUEIRA; STELLA, 2012). A formação histórica e cultural da família brasileira, a partir da divisão sexual do trabalho, da autoridade masculina e de uma organização altamente hierarquizada, propicia a manutenção de valores machistas em nossa sociedade, perpetuando o modelo patriarcal através das gerações (SEQUEIRA; STELLA, 2012; PASINATO, 2016).

O sistema patriarcal propicia que homens detenham mais recursos que mulheres, desigualdade esta que potencializa os conflitos. No mais, o patriarcado enquanto modelo de organização social propiciou a divisão do trabalho de um modo que não somente gera injustiça social, mas também desigualdade de oportunidades entre homens e mulheres, sendo aqueles mais beneficiados (WHITE; KLEIN, 1996). Como consequência, as mulheres, devido à sua posição de vulnerabilidade nesse arranjo social, têm menos acesso a recursos e, portanto, menos poder de negociação, o que as torna mais suscetíveis às consequências negativas de um eventual conflito familiar.

A violência é a forma mais drástica de conflito familiar, fruto não do conflito em si, mas da incapacidade dos membros da família para geri-lo (INGOLDSBY; SMITH; MILLER, 2004). 
Para Hannah Arendt, a violência nada mais é que a mais flagrante manifestação de poder nas relações sociais - no caso da violência contra mulheres, do poder do gênero masculino sobre o feminino (RITT; CAGLIARI; COSTA, 2009).

A violência intrafamiliar emerge como forma de resolução de conflitos, alimentada pela cultura de violência que está na raiz da sociedade brasileira (SEQUEIRA; STELLA, 2012). A impossibilidade, ou incapacidade, de utilizar outros recursos, como 0 diálogo e a argumentação, levam ao uso da violência, especialmente pelos homens (RITT; CAGLIARI; COSTA, 2009). Isso porque a agressividade masculina é considerada uma característica inata da masculinidade, e, assim, naturalizada, justificada - e até mesmo incentivada como método corretivo (RITT; CAGLIARI; COSTA, 2009). O sistema social patriarcal justifica e perdoa a violência conjugal, bem como outras formas de subjugação feminina, sob o discurso de colocar as mulheres desviantes "em seu lugar" (WHITE; KLEIN, 1996; IPEA, 2014).

Por fim, interessante destacar que, proporcionalmente, as meninas foram mais propensas a desenvolver suas respostas a partir de uma perspectiva de gênero. Pode-se deduzir que, enquanto mulheres, são mais sensíveis a esse ponto de vista por vivenciarem na carne as limitações que lhes são socialmente impostas por causa de seu gênero, o que é endossado pelo caráter confessional de muitos textos, nos quais se percebeu alta carga de subjetividade.

\section{Uso de álcool e outras drogas}

O uso de álcool e de outras drogas pelo agressor foi apontado por $35,4 \%$ dos participantes como causa da violência doméstica e familiar contra as mulheres, aparecendo, na maioria dos textos, associado a outros fatores. Apenas 16 redações abordaram exclusivamente o uso dessas substâncias como causa da violência, como se exemplifica com os trechos seguintes.

Devido ao grande número de alcoolismo, drogas, é que vem crescendo a violência em casa. ( $3^{\circ}$ ano, feminino)

Antigamente não ouvia falar esses tipos de violência, mas a maioria é por causa das drogas, das bebidas e tudo o mais... ( $3^{\circ}$ ano, feminino)

De forma geral, os textos afirmavam que o uso de álcool e de outras drogas potencializa a ocorrência de um desfecho negativo em caso de conflito. Recorrentemente foi citado que essas substâncias fazem o homem "perder a cabeça", "perder o controle", agindo irracional e desproporcionalmente diante de problemas que se colocam no dia-a-dia, como a falta de dinheiro, que foi mencionada por vários participantes. Muitos textos ressaltaram, ainda, que 
especialmente sob a influência de álcool e de drogas as agressões acabam ocorrendo por "motivos banais", "fúteis", "desnecessários", como o atraso em servir o jantar ou a não realização de alguma outra tarefa doméstica; ou, ainda, que muitas vezes o homem, embriagado, desconta na família frustrações vivenciadas fora de casa (no trabalho, por exemplo).

Quase a totalidade dos textos que citaram o uso de álcool e drogas associou-no a outros fatores, podendo-se inferir que a maioria dos participantes tinha a noção de que o consumo dessas substâncias, por si só, não é suficiente para causar os abusos.

Muitos usam a bebida como desculpa; bebida não é desculpa pra nada. Ela te dá coragem para fazer aquilo que você queria a muito tempo, ela desperta seu subconsciente, ou seja, sempre esteve ali, só faltava você ver. ( $2^{\circ}$ ano, feminino)

De fato, a literatura evidencia o abuso de álcool e drogas como fator que aumenta significativamente a probabilidade de uma resolução violenta do conflito familiar e conjugal. Todavia, necessário destacar que essa não é precipuamente uma causa, e sim um fator desencadeador, ou agravante, da violência doméstica e familiar, na medida em que tais substâncias agem como desinibidoras, potencializando o conflito (PEREIRA et al, 2013; VIEIRA et al, 2014).

A indicação do uso de álcool ou drogas, especialmente, deve ser problematizado, pois como lembram Bonetti, Pinheiro e Ferreira (2008), o "mito do agressor adicto" (p. 10) retira do agressor a responsabilidade sobre seus atos, pois ele agiria motivado pelo vício, e não autonomamente. Rosa et al (2008) descrevem que homens que cometem violência comumente justificam seu comportamento com o uso de álcool, de modo que o agressor revela "uma incapacidade de experimentar culpa e de aprender com a experiência, tornando-se vulnerável à reincidência" (p. 157). Além disso, existe um forte componente de gênero também no consumo de álcool, que é culturalmente destinado a homens, como lembra Vieira (2014).

\section{Discordância do casal, ou de familiares, sobre alguma questão}

Cerca de $30 \%$ dos participantes apontaram como causa da violência doméstica e familiar contra mulheres a existência de discordância entre o casal, ou familiares, sobre alguma questão. Foram contabilizadas nessa categoria as redações que não apresentavam uma perspectiva de gênero, ou seja, não citavam, de forma explícita, machismo (ou expressões similares). Essa perspectiva foi proporcionalmente mais comum entre os adolescentes do gênero masculino do que entre as adolescentes do gênero feminino. 
As motivações apontadas para tais desentendimentos, por sua vez, foram diversas: intriga feita por outras pessoas, ciúmes, falta de dinheiro, adultério (ou desconfiança sobre). Ciúmes e traição foram as causas mais mencionadas.

Embora não tenham feito menção a questões correlatas ao machismo ou à desigualdade de gênero em nenhum momento de seus textos, esses participantes abordaram conflitos que são resultado da conjuntura patriarcal e misógina sobre a qual se estruturam os relacionamentos afetivos e familiares. Da análise dos textos, percebeu-se que os conflitos, nas narrativas desses alunos, emergiam a partir da tentativa masculina de controlar a mulher (a roupa, onde vai, com quem vai...), e da negativa feminina em obedecer; ou da necessidade masculina de impor/reafirmar sua autoridade, perante alguma frustração.

Não obstante, esses participantes não abordaram as questões sociais que fomentam esses desentendimentos e, consequentemente, a violência. Foram tratadas como resultado de ações individuais dos envolvidos, desconsiderando o pano de fundo sobre o qual se desenrolam tais situações. Assim, enfrentaram as causas da violência doméstica e familiar contra as mulheres como um problema privado, e não como problema social.

A violência doméstica e familiar muitas vezes vem dos desentendimentos de objetos diferentes como o celular. Muitas vezes as mulheres usam o celular e o Whatsapp, e na maioria das vezes o homem não gosta, daí começa rolar os desentendimentos e muitas das vezes a violência. ( $3^{\circ}$ ano, masculino)

A violência doméstica contra as mulheres é a forma do homem se desestressar do trabalho, da vida lá fora para dentro de casa. Por causa da raiva e da forma que o homem é tratado na rua ele acha um jeito de descontar sua raiva, em cima da família e principalmente na mulher. ( $2^{\circ}$ ano, masculino)

Esse dado é bastante relevante por dois motivos. Primeiramente, aponta que uma parcela significativa dos participantes aparentava não ter conhecimento sobre a assimetria na posição de homens e mulheres na nossa sociedade, tampouco sobre as consequências dessa desigualdade para as relações familiares e afetivas; assim, não compreendiam as questões subjacentes aos conflitos, como a organização familiar baseada em um modelo patriarcal e na divisão sexual do trabalho. Portanto, não vislumbravam que a violência contra as mulheres é violência de gênero, resultado de uma cultura misógina e um problema social/público (BLAY, 2003; PASINATO, 2016).

Um dos desdobramentos negativos dessa ausência de perspectiva de gênero entre os participantes é que fica claro, nas redações, que esses alunos não identificavam certos comportamentos masculinos como violentos ou abusivos. O poder exercido pelo homem sobre sua companheira ou filhos era visto, senão como algo positivo, pelo menos como normal, e identificado como zelo. Só a violência explícita, exteriorizada por agressões físicas ou 
assassinato, parecia ser notada por esses adolescentes, indicando a naturalização e a banalização da violência.

O segundo ponto é que muitas redações foram contraditórias, pois, ao mesmo tempo em que condenavam a agressividade masculina, consideravam que a mulher dava ensejo à violência, ou seja, culpabilizavam a vítima. Essa abordagem foi comum principalmente entre os textos produzidos por alunos, de ambos os gêneros, do $1^{\circ}$ ano.

Nesse sentido, uma aluna, por exemplo, afirmou que "as mulheres devem parar de dar motivos para os homens" agredi-las; enquanto um aluno afirmou que deve-se "dar mais valor às mulheres, principalmente às que merecem". Outra participante escreveu que "essas consequências [da violência doméstica e familiar] são muito injustas, até mesmo porque nem todas as mulheres merecem passar por isso." Fica evidente que classificavam as mulheres, fazendo lembrar a popular categoria de "mulher direita", sendo que essa, sim, não merece apanhar.

Pode-se inferir que, na visão desses adolescentes, os papeis sociais destinados a homens e mulheres estavam bem definidos, cada um devendo ater-se ao bom cumprimento do seu respectivo encargo, para haver harmonia na família ou entre o casal. O trecho seguinte é bastante ilustrativo nesse sentido.

A violência doméstica e familiar é aquela que ocorre dentro de casa, muitas vezes por causa da bebida, das drogas. Muitas vezes por causa de conversa mau falada. Porque as mulheres não exercem seu papel na sociedade como deve ser exercido, daí começa ficar tudo fora do comum, daí a mulher começa a não exercer seu papel fundamental, ou seja, seu papel familiar. ( $3^{\circ}$ ano, masculino)

A análise dos textos revelou que, para muitos adolescentes, diante de desentendimentos e conflitos, caberia à mulher controlar e contornar a agressividade masculina, garantindo 0 equilíbrio familiar. Especialmente se houver o uso de álcool ou drogas pelo agressor, as mulheres deveriam ser compreensivas e evitar entrar em atrito.

[...] as mulheres devem deixar os homens em paz no dia que ele chegar bêbado em casa ou estressado com o trabalho, e conversar com ele no dia seguinte quando ele estiver calmo e não bêbado. ( $2^{\circ}$ ano, masculino)

Essa percepção está intimamente ligada à crença nos papeis sociais femininos e masculinos que esses participantes manifestaram, cujas visões são engessadas por estereótipos dos quais não conseguem se desvencilhar - impedindo uma análise crítica ou mais profunda sobre a violência. Acreditavam que a masculinidade está naturalmente associada à raiva, à agressividade e ao espírito de liderança, cabendo às mulheres fornecer o contraponto que possibilita a paz familiar, sendo mansas e submissas. Assim, quando a mulher 
se afasta do papel que lhe caberia, estaria proporcionando a desarmonia do lar, e, consequentemente, a violência. Inclusive, ao condenar a violência contra as mulheres, muitos adolescentes recorreram ao discurso de que mulheres devem ser "protegidas", pois são "frágeis", "delicadas", endossando os estereótipos de gênero.

\section{"Outros"}

As redações cujas abordagens foram classificadas em "outros" corresponderam a aproximadamente $20 \%$ do total, e aqui foram agrupadas as respostas com frequência de repetição baixa (menor que dez). Como exemplos, algumas das abordagens utilizadas foram: a violência doméstica e familiar contra mulheres seria causada pela "falta de diálogo"; "porque os homens são mais nervosos"; "porque as mulheres são mais fracas que os homens"; dentre outros.

Algumas redações afirmaram que o fato de as vítimas não denunciarem, ou de serem passivas diante dos abusos, é uma causa para a ocorrência de violência.

Esses tipos de violência existem por causa da falta de coragem das vítimas, de denunciar os agressores. ( $3^{\circ}$ ano, masculino)

Como o agressor é uma pessoa descontrolada ele não consegue se conter e começa agredindo verbalmente até partir para a violência física, como a maioria das mulheres abaixa a cabeça e não denunciam as agressões continuam acontecendo. ( $2^{\circ}$ ano, feminino)

As mulheres que são abusadas por pessoas da família isso só acontece porque a pessoa é muito submissa, ou não tem muita esperteza de sair do relacionamento antes que algo assim aconteça, pode ser por amor ou por idiotice que algo assim aconteça. Mas tudo depende da força de vontade ou até mesmo saber onde está se metendo. Não se entra na jaula de um leão esperando sair totalmente ileso. ( 2 ano, masculino)

Novamente, evidencia-se a culpabilização da mulher em situação de violência e a privatização do problema, ao relegar a ela a responsabilidade sobre as agressões, como se a violência só ocorresse porque a mulher aceita; desconsiderando todas as nuances (questões emocionais, financeiras, sociais) que dificultam o rompimento do ciclo de violência, e mesmo as burocracias que permeiam o processo de denúncia.

\section{CONCLUSÕES}

Este artigo buscou analisar o conhecimento objetivo, as concepções morais e subjetividades dos adolescentes participantes, a respeito do que consideravam ser as causas da violência doméstica e familiar contra as mulheres. Prevaleceram como causas, na opinião 
dos participantes: o machismo; o uso de álcool e de drogas ilícitas; e discordâncias entre o casal ou a família. Ressalta-se que a maioria dos participantes não elaborou textos com perspectiva de gênero, não obstante seja o contexto social e cultural que fomenta esse tipo de violência.

Notou-se a prevalência de opiniões formuladas a partir das experiências pessoais dos adolescentes, de suas realidades familiares e comunitárias. Também foi possível deduzir grande influência do discurso midiático sobre as percepções dos alunos, podendo-se considerar que a mídia provavelmente assume maior importância, enquanto formadora de opinião desses adolescentes, diante da ausência de discussões sobre o tema em ambiente escolar. Diversos textos analisados apontaram para a permanência de valores machistas entre os adolescentes, especialmente entre os meninos. Problematiza-se que, por não terem, na escola, o acesso formal a conhecimentos sobre o tema, eram levados a abordar o problema de forma superficial e até contraditória - condenando a violência cometida pelo agressor (sobretudo a física), mas também culpabilizando a vítima, por exemplo.

O baixo nível informacional pode colaborar para que os indivíduos naturalizem a violência doméstica e familiar, incorporando práticas violentas em seus relacionamentos, ou tolerando-as. O fim da violência de gênero depende da mudança dos paradigmas culturais e sociais que menosprezam e diminuem as mulheres. Outrossim, premente a necessidade de investir-se em estratégias de conscientização e de sensibilização da população, sobretudo voltadas às faixas etárias mais jovens, visando a prevenção primária da violência - o que deve ser feito não somente nas escolas, mas também através da mídia, que parece influenciar muito significativamente a percepção dos adolescentes. Quanto às iniciativas a serem desenvolvidas em âmbito escolar, salienta-se que ações esparsas, como palestras eventuais, parecem não ser eficientes, sendo necessária uma política educacional perene e contundente, de modo que toda a trajetória escolar seja pautada na educação em direitos humanos (SINGULANO, 2018).

\section{REFERÊNCIAS}

ALVES, Cláudia. Violência doméstica. Faculdade de Economia da Universidade de Coimbra. Coimbra, 2005. Disponível em <http://www4.fe.uc.pt/fontes/trabalhos/2004010.pdf>. Acesso em: 21 out. 2016.

BARDIN, Laurence. Análise de conteúdo. Ed. rev e ampl. São Paulo: Edições 70, 2011.

BLAY, Eva Alterman. Violência contra a mulher e políticas públicas. Estudos Avançados, São Paulo, v. 17, n. 49, p. 87-98, set./dez. 2003. 
BONETTI, Aline; PINHEIRO, Luana; FERREIRA, Pedro. Violência contra as mulheres e direitos humanos no Brasil: uma abordagem a partir do Ligue 180. In: XVI Encontro Nacional de Estudos Populacionais, 2008, Caxambu-MG. Anais eletrônicos... Disponível em <http://www.abep.org.br/publicacoes/index.php/anais/article/view/1740>. Acesso 04 dez. 2016.

BRASIL. Lei no 11.340, de 07 de agosto de 2006. Disponível em <http://www.planalto.gov.br/ccivil_03/_ato2004-2006/2006/lei//11340.htm>. Acesso em: 02 nov. 2016.

CABRAL, Maria Aparecida Alves. Prevenção da violência conjugal contra a mulher. Ciência e Saúde Coletiva, Rio de Janeiro, vol. 4, n. 1, p. 183-191, 1999.

CAMARGO, Márcia (org.). Violência intrafamiliar: orientações para prática em serviço. Brasília: Ministério da Saúde, 2002. 96 p.

CAMPOS, Carmen Hein de. Lei Maria da Penha: necessidade de um novo giro paradigmático. Revista Brasileira de Segurança Pública, São Paulo, v. 11, n. 1, p. 10-22, fev./mar. 2017

CARVALHO-BARRETO, André de et al. Desenvolvimento humano e violência de gênero: uma integração bioecológica. Psicologia: Reflexão e Crítica, Porto Alegre, v. 22, n. 1, p. 86-92, 2009.

CARVALHO, Maria Eulina P. de. Relações de gênero e violências na escola: da compreensão à superação. In: BRABO, Tânia Suely Antonelli Marcelino (Org.). Mulheres, gênero e violência. Marília: Oficina Universitária, São Paulo: Culuta Acadêmica, 2015. Cap. 11. p. 225-246.

CÓRDOBA, Cristina Pintor et al. Violencia doméstica contra la mujer: visión desde la adolescencia. Revista Clínica de Medicina de Familia, Albacete, Espanha, v. 1, n. 3, p. 115120, fev. 2006.

COSER, Lewis A. Social Conflict and the Theory of Social Change. The British Journal of Sociology, [s.I.], v. 8, n. 3, p. 197-207, set. 1957.

DAY, Vivian Peres et al. Violência doméstica e suas diferentes manifestações. Revista de Psiquiatria do Rio Grande do Sul, Porto Alegre, v. 25, n. 1, p. 09-21, abr. 2003.

DIAS, Maria Berenice. A Lei Maria da Penha na Justiça: a efetividade da Lei 11.340/2006 de combate à violência doméstica e familiar contra a mulher. $3^{a}$ ed. rev., atual. e ampl. São Paulo: Revista dos Tribunais, 2012. 340 p.

ENGELS, Friedrich. A Origem da Família, da Propriedade Privada e do Estado. 1ª ed. São Paulo: BestBolso, 2014. 224 p.

FLICK, Uwe. Desenho da pesquisa qualitativa. Porto Alegre: Bookman: Artmed, 2009. 164p.

FRANCO, Luis Rodríguez; LÓPEZ-CEPEIRO, Javier; DÍAZ, Francisco Javier Rodríguez. Violencia doméstica: una revisión bibliográfica y bibliométrica. Psicothema, Oviedo, Espanha, v. 21, n. 2, p. 248-254, 2009.

GIDDENS, Anthony. Sociologia. Tradução de Sandra Regina Netz. 4ํa ed. São Paulo: Artmed, 2005. 597 p. 
GRAY, David E. Pesquisa no mundo real. 2ª ed. Porto Alegre: Penso, 2012. 488 p.

GUIMARÃES, Marina Oliveira. Direito e gênero: a percepção da violência contra a mulher e da Lei Maria da Penha na comarca de Ponte Nova/Minas Gerais. 2012. 135 p. Dissertação (Mestrado em Economia Doméstica). Universidade Federal de Viçosa, Viçosa-MG.

IBGE - INSTITUTO BRASILEIRO DE GEOGRAFIA E ESTATÍSTICA. Resultado IBGE Cidades 2016. Disponível em <https://cidades.ibge.gov.br/brasil/mg/ervalia/pesquisa/13/5902>. Acesso em: 18 out. 2017.

INGOLDSBY, Bron B.; SMITH, Suzanne R.; MILLER, J. Elisabeth. Chapter 5: Conflict Theory. In: Explaining Family Theories. [s.I.]: Roxbury, 2004. p. 103-113.

IPEA - INSTITUTO DE PESQUISA ECONÔMICA APLICADA. Sistema de Indicadores de Percepção Social: Tolerância social à violência contra mulheres. 2014. Disponível em:<http://www.ipea.gov.br/portal/index.php?option=com_content\&view=article\&id=244>. Acesso em: 12 mar. 2017.

KLEIN, David M.; WHITE, James M. Chapter 7: The Conflict Framework. In: Family Theories: An introduction. Thousand Oaks: Sage Publications, 1996. p. 179-210.

MIRANDA, Cynthia Mara. Violência de gênero nos meios de comunicação: reflexões preliminares e desafios para superação. In: STEVENS, Cristina et al (org.). Mulheres e violências: interseccionalidades. Brasília-DF: Technopolitik, 2017. p. 357-366. E-book. Disponível em: <https://www.geledes.org.br/wp-content/uploads/2017/03/Mulheres-eviol\%C3\%AAncias-interseccionalidades.pdf>. Acesso em: out. 2017.

OMS - ORGANIZAÇÃO MUNDIAL DA SAÚDE. Prevenção da violência sexual e da violência pelo parceiro íntimo contra a mulher: ação e produção de evidência. 2012. 94 p. Disponível em: <http://apps.who.int/iris/bitstream/10665/44350/3/9789275716359_por.pdf?ua=1>. Acesso em: 10 out. 2016.

ONU MULHERES. \#Elesporelas: Movimento ElesPorElas (HeForShe) de Solidariedade da ONU Mulheres pela Igualdade de Gênero - Visão Geral. [s.d.]. Disponível em: <http://www.onumulheres.org.br/wp-content/uploads/2015/03/ElesPorElas_visao_geral.pdf>. Acesso em: 14 mar. 2017.

PASINATO, Wânia (coord.). Diretrizes Nacionais Feminicídio: investigar, processar e julgar com perspectiva de gênero as mortes violentas de mulheres. Brasília: ONU Mulheres, Secretaria de Políticas para Mulheres e Secretaria Nacional de Segurança Pública, abr. 2016. 127 p. Disponível em < http://www.onumulheres.org.br/wpcontent/uploads/2016/04/diretrizes_feminicidio_FINAL.pdf>. Acesso em: 02 jan. 2017.

PEREIRA, Rita de Cássia Bhering Ramos. O fenômeno da violência contra a mulher: tipificações e percepções. 2012.105 p. Dissertação (Mestrado em Economia Doméstica). Universidade Federal de Viçosa, Viçosa-MG.

PEREIRA, Rita de Cássia Bhering Ramos et al. O fenômeno da violência patrimonial contra a mulher: percepções das vítimas. Oikos, Viçosa, MG, v. 24, n.1, p. 207-236, 2013. 
PLAN INTERNACIONAL BRASIL. Por ser menina no Brasil: Crescendo entre Direitos e Violências - pesquisa com meninas de 6 a 14 anos nas cinco regiões do Brasil, 2014. Resumo executivo. 30 p. Disponível em < https://plan.org.br/por-ser-menina-no-brasil-crescendo-entredireitos-e-viol\%C3\%AAncia>. Acesso em: 14 mar. 2017.

RABELO, Iglesias Fernanda de Azevedo. Separação e divórcio: conflitos conjugais e qualidade de vida. 2008. 116 p. Dissertação (Mestrado em Economia Doméstica). Universidade Federal de Viçosa, Viçosa, MG.

RITT, Caroline Fockink; CAGLIARI, Cláudia Taís Siqueira; COSTA, Marli Marlene da. Violência contra a mulher compreendida como violência de gênero. Núcleo Interdisciplinar de Estudos sobre Mulher e Gênero da Universidade Federal do Rio Grande do Sul (NIEM), Porto Alegre, 2009.

ROCHA, Diego Vinícius Mattos da; GONÇALVES, Mariane; DAROSSI, Michele. Violência doméstica contra a mulher: breve análise sobre a igualdade entre homens e mulheres no decorrer de situações históricas. Revista da Unifebe, Brusque, n. 07, p. 1-13, 2009.

ROSA, Antônio Gomes da et al. A violência conjugal contra a mulher a partir da ótica do homem autor da violência. Saúde e Sociedade, São Paulo, v. 17, n. 3, p. 152-160, set. 2008.

SANTOS, Benedito Rodrigues dos; MORA, Gabriela Goulart; DEBIQUE, Flávio Antunes (coords.). Empoderamento de meninas - Como iniciativas brasileiras estão ajudando a garantir a igualdade de gênero. Brasília: INDICA, 2016. 100p. Disponível em < https://www.unicef.org/brazil/pt/caderno_meninas_web.pdf>. Acesso em: 14 mar. 2017.

SANTOS, Leonardo Bis dos. O conflito social como ferramenta teórica para interpretação histórica e sociológica. Boletim do Museu Paraense Emílio Goeldi: Ciências Humanas, Belém, v. 9, n. 2, p. 541-553, mai./ago. 2014.

SAXBE, Darby E.; RODRIGUEZ, Aubrey J.; MARGOLIN, Gayla. Chapter 10: Understanding Conflict in Families - Theoretical Frameworks and Future Directions. In: FINE, Mark A.; FINCHAM, Frank D. (Org.). Handbook of Family Theories: A content-based approach. New York: Routledge, 2013. p. 169-182.

SCOTT, Joan W. O enigma da igualdade. Estudos Feministas, Florianópolis, v.13, n.1, p. 1130, jan./abr. 2005.

SEQUEIRA, Vânia Conselheiro; STELLA, Cláudia. Família e violência: resquícios da cultura patriarcal. Emancipação, Ponta Grossa, v. 12, n. 01, p. 71-86, 2012.

SIMMEL, Georg. Questões fundamentais da Sociologia. 1ํㅡ ed. [s.I.]: Jorge Zahar, 2006. 120 p.

SINGULANO, Yara Lopes. Percepções de adolescentes sobre a violência doméstica e familiar contra as mulheres, Ervália/MG. 2018. 136 f. Dissertação (Mestrado em Economia Doméstica). Departamento de Economia Doméstica, Universidade Federal de Viçosa, Viçosa, 2018.

Disponível em: <https://www.locus.ufv.br/handle/123456789/22103>. Acesso em: 20 set. 2019. 
SOUSA, Maria Inês; ASTIGARRA, Andrea. As concepções de gênero - ser mulher - de adolescentes do Bairro do Sumaré - Sobral - CE. Revista de Estudios e Investigación en Psicología y Educación, [s.l.], vol. ext., nº 08, p. 077-081, nov. 2015.

UNICEF - FUNDO DAS NAÇÕES UNIDAS PARA A INFÂNCIA. Empoderamento de meninas, no 2, abril de 2015. 41 p. Disponível em <https://www.unicef.org/brazil/pt/br_empowergirls02.pdf>. Acesso em: 14 mar. 2019.

VIANNA, Cynthia Semíramis Machado. O caso Eloá: análise da abordagem de feminicídio na mídia. In: Fazendo Gênero 9: Diásporas, Diversidades, Deslocamentos, 2010, FlorianópolisSC. Anais eletetrônicos... Disponível em: <http://www.fazendogenero.ufsc.br/9/resources/anais/1278299010_ARQUIVO_semiramiseloafeminicidio.pdf>. Acesso em: 13 out. 2017.

VIEIRA, Letícia Becker et al. Abuso de álcool e drogas e violência contra as mulheres: denúncias de vividos. Revista Brasileira de Enfermagem, Brasília, v. 67, n. 3, p.366-372, jun. 2014.

WAISELFISZ, Julio Jacobo. Mapa da violência 2012: os novos padrões da violência homicida no Brasil. 1ª ed. São Paulo: Instituto Sangari, 2011.

WAISELFISZ, Julio Jacobo. Mapa da violência 2015: homicídios de mulheres no Brasil. 1a ed. Brasília-DF, 2015. 79 p. Disponível em:

<http://www.mapadaviolencia.org.br/pdf2015/MapaViolencia_2015_mulheres.pdf>.Acesso em: 21 out. 2016. 